\title{
C. Langman: Introduction to Vocational Rehabilitation: Policies, Practices and Skills
}

\author{
Routledge, London, 2012, 345 pp. \$56.95 (softbound)
}

\author{
Bruce A. Barron
}

Published online: 6 January 2012

(C) Springer Science+Business Media, LLC 2012

The scope and practice of vocational rehabilitation (VR) is both broad and varied. According to Langman, the field constitutes almost any activity, either structured or unstructured, that supports the return-to-work process. Although VR services vary, the most fundamental elements include an assessment of the worker and his or her medical condition, occupation, and environment. Introduction to Vocational Rehabilitation: Policies, Practices and Skills was published to address knowledge gaps pertaining to government policy and practitioner strategies as it relates to vocational rehabilitation.

The book is organized into three parts. Part 1 defines VR, discusses VR policy in the United Kingdom (UK), reviews the development of pertinent national standards, and discusses other issues such as work disability. Part 2 evaluates various models of VR practice and standards in the UK. The author analyzes services in both the private and public sectors through the application of case studies. The case studies are well designed, enhancing the reader's ability to synthesize and learn basic concepts, principles, and practices. The last section of the book, Part 3, focuses on the knowledge and skills required to provide VR services in a competitive environment. While Part 1 and Part 2 are specific to the UK, Part 3 provides critical information basic to VR practice per se.

Introduction to Vocational Rehabilitation: Policies, Practices and Skills is an interesting read. The book is evidence-based, logically organized, and comprehensive. Inclusion of numerous tables, figures, and case studies facilitate the reader's ability to learn and understand challenging or complex subject matter. Although Introduction to Vocational Rehabilitation: Policies, Practices and Skills presents a state-of-the art review of VR, its value is limited due to the emphasis of policies and practices specific to the United Kingdom. Despite this limitation, students and practitioners from around the world will benefit greatly by reading Part 3 .
B. A. Barron ( $\square)$

Division of Occupational and Environmental Medicine,

University of Rochester School of Medicine and Dentistry,

Rochester, NY, USA

e-mail: bruce_barron@urmc.rochester.edu 